\title{
Correction to: Slope Stability Analysis for Mine Hazard Assessment Using UAV
}

\author{
Sai Charitha Vemulapalli ${ }^{1}$ [D Shashi Mesapam ${ }^{1}$
}

(C) Indian Society of Remote Sensing 2021

\section{Correction to: Journal of the Indian Society of Remote Sensing \\ https://doi.org/10.1007/s12524-020-01239-9}

Unfortunately, the revised Fig. 1 of the article was not published in the original publication. The correct figure is given below.

The original article has been corrected.

The original article can be found online at https:// doi.org/10.1007/s12524-020-01239-9.

\footnotetext{
Shashi Mesapam mshashi@nitw.ac.in

Sai Charitha Vemulapalli vemulapallisai@student.nitw.ac.in

1 Department of Civil Engineering, NIT Warangal, Warangal 506004, India
} 


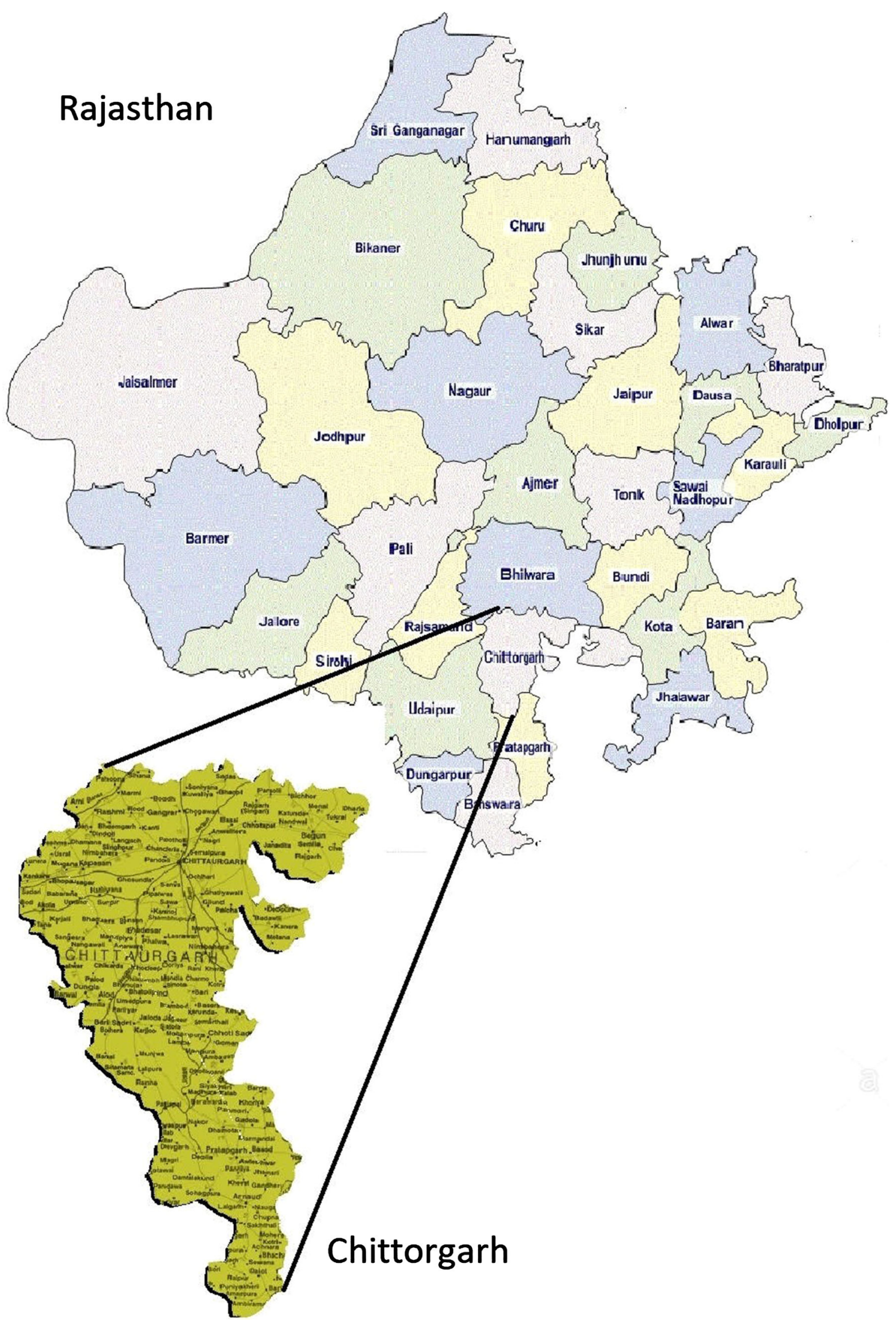

Fig. 1 Location of study area 